\title{
Soviet academy's restructuring policy causes voting problems
}

London

THE Soviet Academy of Sciences has been voting in the first of three batches of elections that will bring in some 250 new members and corresponding members. This massive influx is a result of the new "cadre restructuring" policy. From now on, when an academician reaches 75 years of age, his position will be deemed vacant and a replacement elected. Academicians and corresponding members will have to retire from administrative posts in the academy research network at the age of 70 and other administrators at 65. But although these changes were approved by a general meeting of the academy early last year, the run-up to the elections has evoked discussion on the purpose and role of the academy.

According to Pravda, the leadership stated in September that nominees for the vacant places must be under 60 for election as full academicians and under 55 for corresponding members. But when the lists were drawn up in October, many scientists over 60 were included.

A number of academy members think the age limit contravenes the academy's statutes. Others feel that the limit would be detrimental to science. In particular, many stress that inherent conflict in the double role of the academy - as an association of eminent scientists, with membership bestowed as the crowning honour of a brilliant career, and as the principal coordinator and organizer of research in the Soviet Union.

There has been less opposition to the compulsory retirement of superannuated administrators (12 senior academicians have already resigned under this rule) than on the upper age limit on election. Almost a third of the existing members of the academy, it is argued, were elected only when past 60 , and some deserving scientists over 60 will now be excluded for life from an honour they would otherwise almost certainly have received in the next few years.

Moreover, it would not be simple to devise an interim solution that would allow, for the next decade or so, the existence of supernumerary members drawn from deserving but now over-age scientists. For academy membership involves not merely a title of honour but also a salary and fringe benefits. Some scientists now question this system, which although not unique to the Soviet Union is out of step with general world practice. If scientists are paid by their work, it is argued, rather than for their title, they will be encouraged to produce tangible results.

Abolishing academic salaries and benefits, moreover, would help to put an end to the current 'back-door' admissions. Scientific administrators and directors of institutes are frequently elected to the academy as a matter of routine. And such members not only have little to offer in terms of scientific achievement, but have also, it is argued, introduced an "alien bureaucratic style".

The new rules on compulsory retirement will inevitably entail a major influx of new administrative personnel into the academy institutes, making it all the more important to end the practice of routinely electing such officials to academy membership. Suggested measures include stricter assessment of the scientific work of those proposed for election, greater 'democratization' of the elections (with corresponding as well as full members of the academy being allowed to vote) and a

special arrangement for the Siberian, Far Eastern and Ural branches, allowing those who work there to be made 'candidate members' of the branch.

In spite of numerous calls to "restructure" personnel policy, the old scheme of routine promotions still to some extent persists. One proposal voted on last month was the nomination of Aleksander Zhuchenko to be director of the academy's Institute of General Genetics. Zhuchenko, originally an agronomist, rose to be president of the Moldavian Academy of Science, largely due to the patronage of the now-disgraced first secretary of Moldavia, Ivan Bodul. Since Bodul's fall, Zhuchenko has come under severe attack for the agricultural policy he urged on the Moldavian authorities, which has led to the erosion and salination of considerable tracts of land. The fact that he could nevertheless be proposed to be director of one of the academy's most important institutes indicates, perhaps, the scale of the problem.

Vera Rich

\section{West Germany looks for the neural-network connection}

\section{Munich}

Anxious about losing the race to build neural-network computers, West Germany is beginning a three-year project in January 1988. 'Information processing in neural architectures' will be funded with DM3 million in 1988 and possibly much more in the future.

The project represents an "extraordinary effort" by the West German Research and Technology Ministry (BMFT), says Rolf Eckmiller of the University of Düsseldorf, one of the project's beneficiaries. Nine groups will be funded, with three or four new positions at the universities of Düsseldorf and Bochum. This stands to make the Land of North RhineWestphalia, where these universities are located, "not only the German centre but the European centre as well" for research on neural networks, says Eckmiller.

The goals of the project are twofold: to transfer knowledge about how the brain functions to the design and programming of new parallel computers; and to develop intelligent robots that will be able, using neural processing, to "see, hear, write, speak" and otherwise respond to their environment

Despite the excitement in US, Japanese and European laboratories about the commercial potential of neural-network computers, BMFT is not pushing West German researchers exclusively towards applications. "The BMFT's goal is to support basic research", according to one project leader, Klaus Schulten of the Technical University of Munich. "They're not pressing us to come up with something that can be sold within five years." International competition will be stiff. According to one estimate, the United States is far in advance, with roughly $2,500-3,000$ researchers working in the field. Japan follows with $100-500$ people. In the European Economic Community (EEC), there are $500-1,000$ researchers, $100-300$ of them in West Germany.

The EEC has its own programme, entitled BRAIN (Basic. Research in Adaptive Intelligence), to support research in neural networks. But its funds are not awarded on scientific merit alone, priority being given to groups that collaborate internationally. Funds are also available through another European programme, ESPRIT II

The interdisciplinary nature of neuralnetwork research makes it unpopular in the more rigid of the West German universities. In fact, Schulten moves to a US university in 1988 where he will not be "isolated and looked down upon". He will take his entire research group with him when he goes. The group is trying to programme a robot to learn from its own mistakes, for example in distinguishing and manipulating blocks of different shapes and colours.

For Research and Technology Minister Heinz Riesenhuber, the fact that good people are leaving provides a compliment to the quality of West German research but a compliment that is not entirely welcome. In a recent television interview he said that one goal of the new project is to keep good people in West Germany.

Steven Dickman 